\title{
OS FUNDAMENTOS POLÍTICOS DA CONCORRÊNCIA: ALINHANDO A DEFESA DA CONCORRÊNCIA COM A CONSTITUIC̣ÃO ECONÓMICA E O MODELO ECONÓMICO-SOCIAL PORTUGUÊS
}

\author{
NUNO CASTRO MARQUES \\ PROFESSOR AUXILIAR DA FACULDADE DE DIREITO E CIÊNCIA POLIITICA DA ULP \\ COORDENADOR DE LINHA DE INVESTIGAÇÃO "DIREITO ALÉM-FRONTEIRAS" DO CENTRO DE ESTUDOS \\ AVANÇADOS EM DIREITO FRANCISCO SUÁREZ (CEAD - FRANCISCO SUÁREZ)
}

\begin{abstract}
: recent proposals on procedural framework of competition law justify revisiting the theme of the legal interests proytected by competition laws, questioning whether it is sustainable to maintain an idea that competition law aims (only) to defend economic efficiency or consumers when competition defense entities are continuously entrusted with more and new powers which undoubtedly pertain to the tool kit for investigation of particularly serious criminal offenses.
\end{abstract}

KEYWORDS: competition law; restrictive practices; legal interests

RESUMO: as recentes propostas de evolução do quadro jurídico-processual e investigatório do direito da concorrência justificam que se revisitem os fundamentos e bens jurídicos tutelados pelas normas de defesa da concorrência, questionandose se é sustentável manter-se uma ideia de que o direito da concorrência visa (apenas) defender a eficiência económica ou os consumidores quando se projeta a atribuição às entidades de defesa da concorrência de mais e novos poderes e instrumentos e que se inserem, indubitavelmente, numa lógica de investigação de ilícitos de natureza particularmente grave e, assim, dotados de dignidade penal.

KEYWORDS: Concorrência; práticas restritivas; bens jurídicos

SUMÁRIO: 1. Introdução e enquadramento 2. Idos os tempos da panaceia da eficiência económica ... 3. Back to basics? ... os fundamentos políticos da defesa da concorrência 3.1 Os bens jurídicos protegidos pelo direito europeu da concorrência 3.2 A dignidade constitucional dos bens jurídicos protegidos pelo direito nacional da concorrência 4. Retome-se o sentido das palavras ... o texto constitucional como quadro de referência delimitador da atividade punitiva do Estado.

\section{Introdução e enquadramento}

A Proposta de Lei n. ${ }^{\circ} 99 / \mathrm{XIV} / 2{ }^{\circ}$, que visa transpor para o ordenamento jurídico nacional a Diretiva (UE) 2019/1, conhecida por Diretiva ECN+ ${ }^{1}$, pelas vicissitudes que já motivou desde a sua apresentação em resultado das questões que suscita, constitui o leitmotiv para revisitarmos o tema dos bens jurídicos tutelados pelas normas de defesa da concorrência e, consequentemente e também, o da natureza jurídica que tais normas poderiam - ou quiçá deveriam - apresentar. A referida iniciativa legislativa foi apresentada a 21 de maio do 2021 e propõe múltiplas alterações à Lei n. 19/2012, de 8 de maio, que aprova o regime jurídico da concorrência (doravante Lei da Concorrência ou LdC), bem como ao DecretoLei n. 125/2014, de 18 de agosto, quo aprovou os estatutos da Autoridade da Concorrência. Tais alterações são motivadas pela necessidade de adequação do regime jurídico da concorrência à Diretiva ECN+, que deveria já ter sido transposta até 4 de fevereiro de 2021. A Diretiva, por seu turno, pretende harmonizar os regimes jurídicos de defesa da concorrência dos Estados-Membros para aumentar

\footnotetext{
1 E que pretende atribuir às autoridades da concorrência dos Estados-Membros competência para aplicarem a lei de forma mais eficaz e garantir o bom funcionamento do mercado interno.

2 Para uma análise transversal da Diretiva ECN+, ver (GORJÃO-HENRIQUES \& SAAVEDRA, 2020)
}

$$
2
$$


a efetividade das atuações das suas autoridades nacionais de concorrência. Com esse desiderato, a Diretiva ECN+ ${ }^{1}$ abrange um conjunto muito vasto de aspetos, todos eles relevantes, como sejam o reforço da independência das autoridades nacionais de concorrência, a garantia de um conjunto mínimo de meios financeiros, técnicos e tecnológicos considerados necessários ao cumprimento efetivo das suas atribuições e competências, o aprofundamento da cooperação entre autoridades no seio da ECN, bem como a cooperação com os tribunais nacionais, a garantia de reconhecimento de competências inspetivas e meios de investigação suficientes, harmonização dos meios de prova admissíveis e competências sancionatórias e, ainda, a harmonização dos programas de clemência em caso de cartéis. ${ }^{2}$

Ocupar-nos-emos apenas de uma parte de tais aspetos, até considerando que a motivação de reflexão adveio, como referido, das vicissitudes que a Proposta de Lei n. $99 / \mathrm{XIV} / 2$. $^{a}$ já conheceu e que se relacionam com a consideração de que as alterações propostas aos artigos $18 .^{\circ}$ e $31 .^{\circ}$ da $\mathrm{LdC}$ se apresentam como não conformes ao n. 4 do artigo $34 .^{\circ}$ da Constituição da República Portuguesa ${ }^{3}$, porquanto tais alterações propostas permitiriam à Autoridade da Concorrência a ingerência na correspondência e outros meios de comunicação privada, bem como a utilização desses elementos como meio de prova.

Em concreto, a proposta de alteração ao art. 18. da LdC apresenta(va) uma alínea b) que pretendia estabelecer que a Autoridade da Concorrência poderia "Proceder à busca, exame, recolha e apreensão ou cópia, sob qualquer forma, de informações ou dados, em qualquer formato, físico ou digital, designadamente, documentos, ficheiros, livros, registos ou mensagens de correio eletrónico ou de natureza semelhante, independentemente de parecerem não ter sido lidas ou de terem sido apagadas, qualquer que seja o suporte, estado ou local em que estejam armazenadas, nomeadamente num sistema informático ou noutro a que seja permitido o acesso legítimo a partir do primeiro, servidores, computadores portáteis, telemóveis, outros dispositivos móveis ou outros dispositivos não previamente identificados com precisão, acessíveis ao visado ou à pessoa sujeita a busca e relacionadas com o visado". Por seu turno, a proposta de alteração ao n. 2 do art. 31. da LdC visa(va) assentar que "Constituem meios de prova admissíveis, nos termos do disposto no artigo 167. do Código de Processo Penal, [...] entre outros não expressamente proibidos, quaisquer documentos, declarações orais ou escritas, mensagens de correio eletrónico ou de natureza semelhante, independentemente de parecerem não terem sido lidas ou de terem sido apagadas, gravações, ficheiros e quaisquer outros objetos que contenham informações, independentemente do formato e do suporte em que tais informações se encontrem armazenadas."

Em Nota Técnica dos serviços da Assembleia da República ${ }^{4}$, partiu-se da constatação de que as infrações sancionadas pelo regime jurídico da concorrência correspondem a "[...] ilícitos de mera ordenação social, sancionados com a aplicação de coima e aos quais está associado um menor desvalor ético-jurídico relativamente ao que se verifica no direito criminal. [...] o direito contraordenacional não assegura, ao infrator, as mesmas garantias de defesa que o direito penal confere ao arguido", citando a esse propósito os Acórdãos do Tribunal Constitucional n. $395 / 2014$, processo n. ${ }^{\circ}$ 683/13, em que se expressou o entendimento de que "[...] no ilícito de mera ordenação social, as sanções não têm a mesma carga de desvalor ético que as penas criminais, para além de que, para a punição, assumem particular relevo razões de pura utilidade e estratégia social", e n. ${ }^{\circ}$ 180/2014, processo n. ${ }^{\circ}$ 240/2013, onde se considera que "[...] as diferenças existentes entre o ilícito de natureza criminal e o ilícito de mera ordenação social impede que se possa efetuar uma estrita transposição das normas e princípios constitucionais em matéria penal para o domínio do direito contraordenacional. [...] A contraordenação é um aliud que se diferencia qualitativamente do crime na medida em que o respetivo ilícito e as reações que The cabem não são diretamente fundamentáveis num plano ético-jurídico, não estando, portanto, sujeitas aos princípios e corolários do direito criminal [...]."

Assim suscitadas dúvidas sobre a compatibilidade de tais propostas com o n. ${ }^{\circ} 4 \mathrm{do}$ artigo 34. da Constituição da República Portuguesa, foi solicitada a apreciação da iniciativa legislativa pela Comissão de Assuntos Constitucionais, Direitos, Liberdades e Garantias da Assembleia da República que, em parecer de 14 de julho de $2021{ }^{5}$, concluiu que "As normas dos artigos 18. ${ }^{\circ}$, n. $^{\circ} 1$ alínea bl, e $31 .{ }^{\circ}$, n. 2, da Lei n. 19/2012, na redação constante da Proposta de Lei n. ${ }^{\circ}$ 99/XIV/2. (GOV) que decorrem da transposição da Diretiva (UE) 2019/1, do Parlamento Europeu e do Conselho, de 11 de dezembro de 2018, violam o disposto no artigo $34 .{ }^{\circ},{ }^{\circ}{ }^{\circ}$, da CRP." 6

\footnotetext{
${ }^{3}$ Que que proíbe a ingerência das autoridades públicas na correspondência, nas telecomunicações e nos demais meios de comunicação, com exceção dos casos previstos na lei em matéria de processo criminal

4 Disponivel em https://www.parlamento.pt/ActividadeParlamentar/Paginas/Detalhelniciativa.aspx?BID=110842

${ }^{5}$ Igualmente disponível em https://www.parlamento.pt/ActividadeParlamentar/Paginas/Detalhelniciativa.aspx?BBD=110842

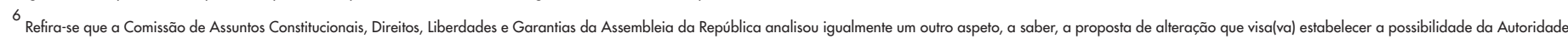

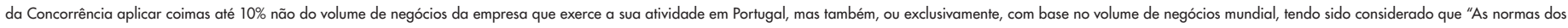

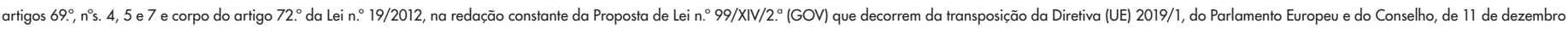
de 2018 , são passíveis de violar o disposto no artigo $266^{\circ}$, n. $^{\circ}$ 2, da CRP."
} 
DOI: 10.46294/ulplr-rdulp.siv 1 a4

Atente-se que se deu por assente que as normas projetadas constituíam transposição da Diretiva ECN+, ou seja, possuíam fonte direta no texto da mesma. Ora, impõe-se questionar como, num ordenamento jurídico regido pelo princípio das competências por atribuição ${ }^{7}$ e (ainda) assente no paradigma de que à União Europeia não foram atribuídas competências penais ${ }^{8}$, pode chegar-se à inusitada situação de que em transposição de uma Diretiva da União Europeia se viola a proibição constitucional de ingerência, ressalvadas as exceções previstas em sede de processo criminal, na correspondência, nas telecomunicações e nos demais meios de comunicação.

Por outro lado, e como já por nós defendido em outra sede ${ }^{9}$, entre os bens jurídicos tutelados pelas normas e as formas de tutela deve verificar-se uma congruência no sentido da adequação e justificação mútua. A cada direito substantivo corresponderá um adjetivo e entre ambos deverá existir suficiente sintonia para que o último permita a correta e eficiente aplicação do primeiro, em prol da efetiva tutela dos bens jurídicos protegidos. Mas as formas de tutela do direito da concorrência deverão forçosamente encontrar a sua legitimação nos bens jurídicos protegidos, donde que, mais uma vez, se impõe uma reflexão sobre o tema dos bens jurídicos tutelados pelas normas de defesa da concorrência e, e, consequentemente e também, o da natureza jurídica que tais normas poderiam ou quiçá deveriam - apresentar.

\section{Idos os tempos da panaceia da eficiência económica}

Com o especial contributo das Escolas de Harvard e de Chicago, a vertente dos fundamentos económicos foi adquirindo proeminência na discussão sobre os objetivos da defesa da concorrência, quiçá empalidecendo outros e mais robustos fundamentos.

Fazendo-se uma breve súmula do que foi o desenvolvimento do conceito de concorrência enquanto elemento fundamental para o desenvolvimento económico, recorde-se que processo concorrencial descrito por ADAM SMITH é um processo de rivalidade entre agentes económicos ${ }^{10}$, ou seja, "a process stimulating rivalry among agents (to improve their performances) by reacting and counter-reacting behaviours. Such a process constitutes the (relative) price system and invisibly coordinates the interaction of market participants." ${ }^{11}$, sendo que para o funcionamento

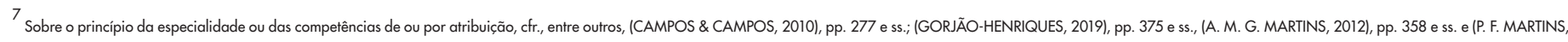
2012).

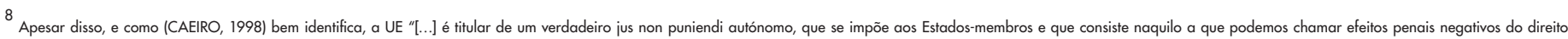

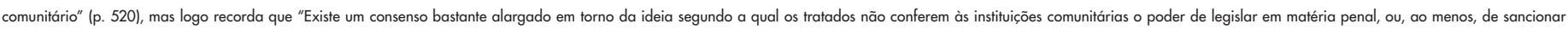

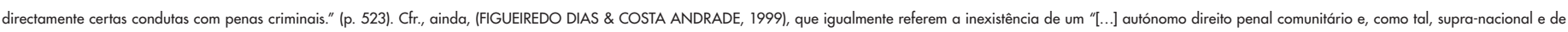
aplicação directa pelos tribunais dos Estados-membros." (pp. 326-327).

9 (CASTRO MARQUES, 2019).

10 Assim (MCNULTY, 1967), p. 395, e (STIGLER, 1957), p. 1

11 (VATIERO, 2010), p. 692.

12 (STIGLER, 1957), p. 2

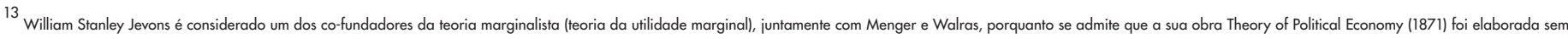

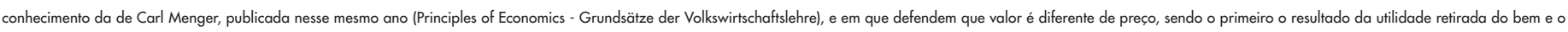

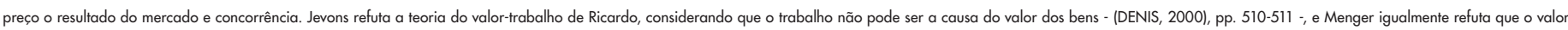

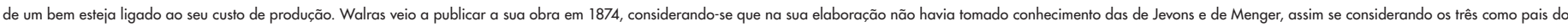
marginalismo - cfr. (DENIS, 2000), p. 523.

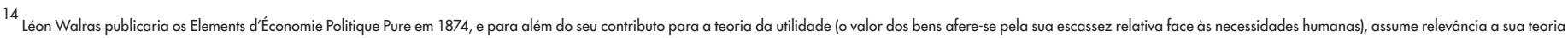

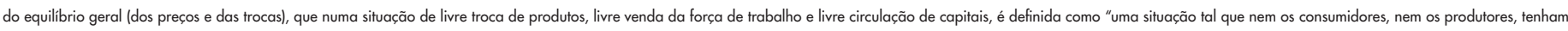
interesse em modificar as quantidades de bens e de serviços que pedem ou que oferecem nos diferentes mercados" - cfr. (DENIS, 2000), p. 525.

${ }^{15}$ A

Assim (CAYSEELE \& BERGH, 2000), p. 470, que referem que um mercado perfeitamente concorrencial passava agora a ser definido à luz de um conjunto de propriedades, como sendo a oferta e a procura serem exercidas por um elevado número

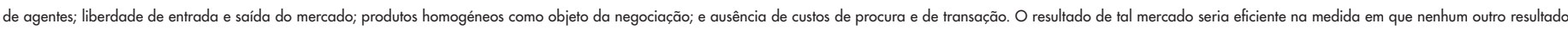

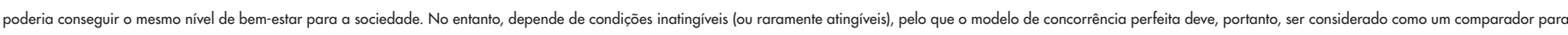
análise de outros tipos de estruturas de mercado. 
correto de tal processo (concorrencial) era (é) necessária, entre outras, a liberdade de atuação dos agentes ${ }^{12}$. E a idealização de um modelo de concorrência perfeita, que vai ainda buscar alguns fundamentos aos trabalhos de JEVONS e MENGER ${ }^{13}$, atinge a sua forma mais trabalhada com WALRAS ${ }^{14}$ e passará a servir de comparador ${ }^{15}$ de todos os restantes modelos de concorrência.

No campo da definição de "eficiência", acrescente-se o conceito que ficou conhecido como o "ótimo de Pareto" e que, em suma, considera uma situação como ótima (em equilíbrio ou eficiente) quando, e já por recurso à sua apresentação hodierna, "o bem-estar de um agente económico ${ }^{16}$ não pode aumentar sem prejudicar o bem-estar de outro agente económico", e que hoje é apresentada como a base do conceito de eficiência alocativa ${ }^{17} 18$. SCHUMPETER aporta a contribuição da inovação na evolução económica e abre campo para a consideração e importância da diferenciação dos produtos e dos agentes no mercado, com uma análise substancialmente dinâmica e de processo, assim se compreendendo a sua creative destruction ${ }^{19}$

Com a Escola de Harvard, o enfoque da análise da concorrência redireciona-se do processo para a estrutura ${ }^{20}$, e o paradigma passa a ser o de que a estrutura determina os comportamentos dos agentes (quer da oferta, quer da procura), os quais condicionam a performance ${ }^{21}$. Estava assim criado o modelo S-C-P ("structureconduct-performance"), associado a uma conceção de defesa da concorrência ${ }^{22}$ que atribuía uma elevada relevância à própria capacidade de enforcement das normas de defesa da concorrência. E com a subsequente Escola de Chicago, por vezes apelidada de "antitrust revolution" 23 , é assumida a racionalidade dos agentes económicos na maximização da eficiência, defendendo-se que o direito da concorrência não deve impedir essa busca de eficiência, enquanto único meio de garantir o aumento do bem-estar do consumidor ${ }^{24}$. Assim, por exemplo, BORK vem defender que o único objetivo da concorrência deverá ser a "maximization of consume want satisfaction" 25 , opor-se à maioria das proibições per se ${ }^{26}$ e tentar limitar os objetivos da concorrência a questões de eficiência ${ }^{27}$ , o que implica garantir a liberdade dos agentes económicos ${ }^{28}$. EASTERBROOK igualmente defenderá como único objetivo da defesa da concorrência a eficiência económica ${ }^{29}$, criticando as proibições per se com exceção das aplicáveis às restrições horizontais "naked", e sendo particularmente cético quanto às intervenções públicas e dos tribunais na apreciação de práticas empresariais no campo da concorrência, as quais não raras vezes prejudicarão as opções racionais dos agentes económicos ${ }^{30} 31$. Posteriormente e de uma forma mais moderada, vem defender a necessidade de identificação clara dos objetivos da concorrência $^{32}$, ainda que sempre cético quanto à capacidade de análise de certas práticas e preferindo a não ingerência nos "falsos negativos" do que a intervenção sobre "falsos positivos" 3334 . Também POSNER, que propugna uma visão mais moderada da Escola de Chicago ${ }^{35}$, parte dos pressupostos da racionalidade dos agentes económicos e dos consumidores, o que conduz a um ceticismo relativamente às intervenções públicas ${ }^{36}$ por contraposição à maior crença nas eficiências (wealth maximization) resultantes das opções dos agentes económicos ${ }^{3738}$

Apesar de algumas críticas, Chicago aportou avanços consideráveis na análise concorrencial e que constituem, hoje, pressupostos relativamente consensuais ${ }^{39}$ e um deles é o da consideração (ou maior relevância) da eficiência económica e do bem-estar (seja do consumidor, seja totall) na defesa da concorrência

Mas este percurso serve aqui o específico propósito de assentarmos um pressuposto que para nós é absolutamente claro, a saber, que os fundamentos económicos para a defesa da concorrência são, naturalmente, cruciais para o desenvolvimento económico mas não serão estes que justificarão o estabelecimento de normas substantivas e adjetivas aptas a comprimirem direitos fundamentais.

\footnotetext{
${ }^{16}$ (ALMEIDA, 2007), p. 10.

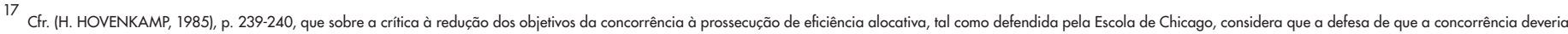

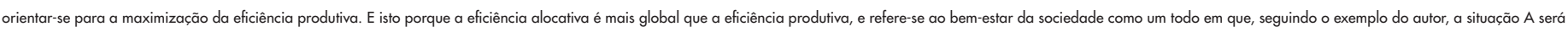

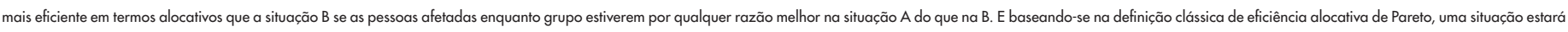

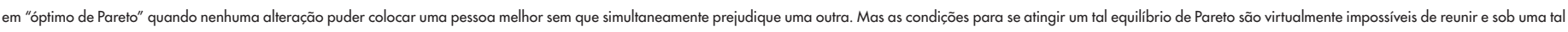

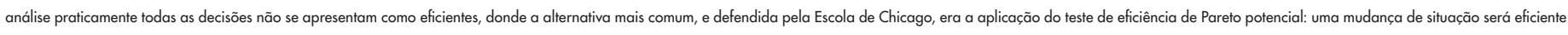

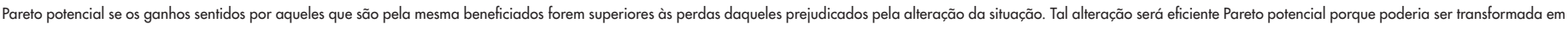

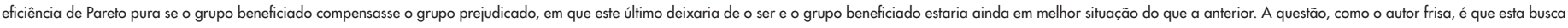

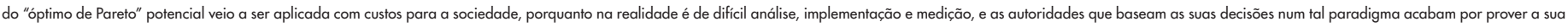
aplicação no sentido de uma situação ser superior em termos de Pareto se ninguém se opuser à mesma, o que não será necessariamente correto.

18 Sobre o conceito de equilibrio de Pareto, cfr. igualmente (ETTER, 2000), pp. 110 e ss., ou (GRAUER, 1989), p. 75. .

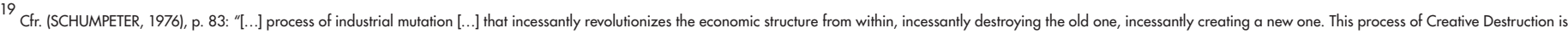
the essential fact about capitalism."
} 
DOI: 10.46294/ulplr-rdulp.siv 1 a4

Dito de outra forma, não será por questões de defesa da eficiência económica ou do bem-estar do consumidor ou da sociedade ${ }^{41}$ que se legitimariam, como na situação que motiva a presente reflexão, ingerências na correspondência, nas telecomunicações e nos demais meios de comunicação para investigação de eventuais práticas contrárias à concorrência ${ }^{40}$.

Tais ingerências, bem como outras diligências de investigação que impactem relevantemente com direitos fundamentais ${ }^{42}$, encontram-se constitucionalmente reservadas para o foro do processo criminal. E o mesmo é dizer que a defesa da concorrência apenas poderá aspirar a recorrer a tais ingerências ou diligências se a mesma visar defender bens jurídicos com densidade, dignidade constitucional, valoração axiológica e justificação ético-social necessárias a que consubstanciem um bem jurídico tutelado por norma penal.

Analise-se se assim é.

\section{Back to basics? ... os fundamentos políticos da defesa da concorrência}

$\bigcirc$ que vimos de apresentar não retira, por qualquer forma, importância aos fundamentos económicos da defesa da concorrência. Pelo contrário, deve atribuir-se ao constante estudo e desenvolvimento dos benefícios (económicos) da concorrência a consciencialização para a importância da sua defesa, bem como para a gravidade dos danos que as violações à mesma podem provocar.

ponto é que essa consciencialização generalizada tem conduzido, também, a um aumento da repressão dos ilícitos jusconcorrenciais ${ }^{43}$, e a Diretiva ECN+ insere-se, claro está, numa tal tendência. Visa, como já visto, aumentar e reforçar as condições de efetividade das atuações das autoridades nacionais de concorrência, designadamente através do estabelecimento de competências inspetivas e meios de investigação suficientes, harmonização dos meios de prova admissíveis e competências sancionatórias e harmonização dos programas de clemência em caso de cartéis, o que conduz, como in casu se constata, a proporem-se competências inspetivas e meios de prova que no nosso ordenamento constitucional se encontram reservados para a investigação de ilícitos de natureza criminal.

Ao direito penal devem ficar reservados, como ultima ratio, apenas os ilícitos mais graves, e o primeiro passo para o fazer é por aplicação do filtro decantador dos bens jurídicos, e do qual resulta que "[p]elo direito penal [...] não deverão ser abrangidas [...] as condutas que, dada a sua neutralidade ético-social, não mais permitem uma referência à ordem axiológica constitucional [...]", sendo que

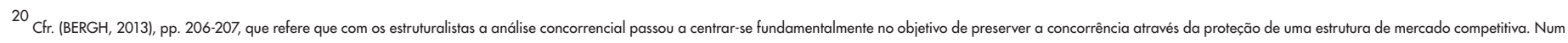
mesmo sentido, mas numa análise mais ampla e comparativa das diversas escolas de pensamento económico, e já englobando a reflexão sobre o modelo europeu, cfr. (HILDEBRAND, 2002).

${ }^{21}$ Cfr. (CAYSEELE \& BERGH, 2000), p. 473

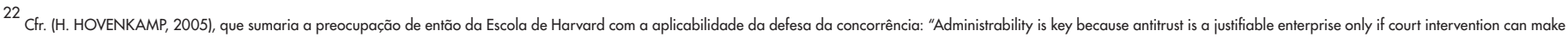
markets work better" (p. 7).

23 Assim, p. ex., (CAYSEELE \& BERGH, 2000), p. 467, (GIFFORD \& SULLIVAN, 2007), p. 436, ou (H. J. HOVENKAMP, 2007), p. 1.

24 Cfr., de novo, (CAYSEELE \& BERGH, 2000), p. 475

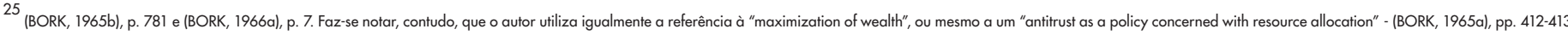
-, e irá evoluir para um conceito de "consumer welfare", que equipara a eficiência, sendo esse um aspeto que os seus críticos apontarão como representativo do pouco rigor de Bork na utilização de conceitos técnicos como sejam os de eficiência económica ou de excedente do consumidor. A esse respeito, cfr., p. ex., (ANDRIYCHUK, 2012), pp. 365-366.

${ }^{26}$ (BORK, 1966b), p. 378, onde defende que a não definição, em termos de bem-estar do consumidor, do âmbito de aplicação das proibições per se estaria na origem da incapacidade do Supremo Tribunal em determinar satisfatoriamente os seus contornos, e defende a distinção, no que respeita às restrições horizontais, entre as restrições "naked" e "ancillary" - p. 384). Já relativamente às restrições verticais, o autor é claro a defender a substituição de uma proibição per se por uma permissão per se ("every vertical arrangement should be lawful" - p. 397). No mesmo sentido, ver ainda e p. ex., (BORK, 1965a), sendo interessante notar que, mesmo no extremo do pensamento de Chicago, aceita e considera sólida a teoria de que os cartéis eliminam a concorrência e não criam eficiências, pelo que devem ser objeto de uma proibição per se, demonstrando serem uma situação totalmente distinta dos outros tipos de (potenciais) restrições à concorrência - p. 410). Também em (BORK \& BOWMAN, 1965), p. 364, é expressa tal concordância com a proibição per se da fixação horizontal de preços, por considerar possuir fundamento económico (prejuízo para o consumer welfare), sendo o mesmo entendimento igualmente defendido por (BOWMAN, 1965), p. 417, ou seja, o de que para os acordos horizontais de fixação de preços é totalmente fundamentada a existência de uma proibição per se.

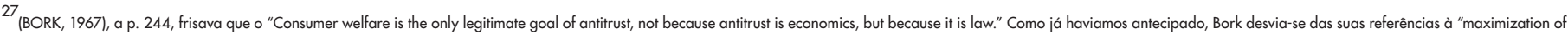
wealth or consume want satisfaction" para utilizar este conceito de bem-estar do consumidor, mas a pp. 251-252 volta a fazer referência ao "maximizing consumer want satisfaction", equiparando-o a eficiência porquanto, como escreve, "I take "efficiency" to be defined in terms of meeting consumer desires. I do not know how else one could measure the value of output." E conclui que "the introduction of goals other than consumer welfare into antitrust is destructive of antitrust as law." (p. 253) 
DOI: 10.46294/ulplr-rdulp.siv 1 a4

deve verificar-se uma "[...] relação, que não é por certo de identidade ou sequer de recíproca cobertura, mas de analogia substancial" ${ }^{44}$ entre a ordem dos bens jurídicos e a ordenação axiológica da Constituição.

Mas a partir do momento que, na defesa da concorrência, se trilha de forma evidente um tal caminho de tutela repressiva, impõe-se, em nosso entendimento, o ressurgimento dos fundamentos políticos da defesa da concorrência - ou, se se quiser, a sua recolocação no lugar de destaque e correspondente à sua primazia -, e que foram sendo ofuscados por uma tendência, agora em perda de fulgor, de privilegiar a discussão dos fundamentos económicos. E isto porque os fundamentos (iniciais e constantes) da defesa da concorrência são estruturalmente políticos e, sobretudo, os únicos que, pela sua dignidade jurídico-constitucional, podem justificar o seu caráter fortemente sancionatório.

Tendo-se presente que estamos perante uma proposta legislativa que visa transpor uma Diretiva europeia, estamos novamente perante uma evidência concreta daquela que tem sido uma caraterística estruturante do direito nacional da concorrência, a saber, a sua forte conformação pelo direito europeu da concorrência. E por tanto se afigura relevante proceder-se à análise do que sejam os bens jurídicos tutelados por tais diferentes normas e identificar os fundamentos políticos e os bens jurídicos protegidos pelos direitos europeu e nacional da concorrência, percebendo-se se os mesmos possuem capacidade para justificar os seus caráteres sancionatórios.

\subsection{Os bens jurídicos protegidos pelo direito europeu da concorrência}

A primeira nota a reter é o cararáter multivalor do direito da concorrência, como oportunamente se verá. GUERRIN \& KYRIAZIS referem-se a bens jurídicos do direito europeu da concorência como o mercado interno, a proteção do consumidor e a alocação óptima dos recursos e investimentos, relacionados com a opção fundamental de controlar a acumulação de poder económico privado ${ }^{45}$. HARGITA \& TÓTH acrescentam o valor da transparência ${ }^{46}$ e KOKKORIS recorda que os fundamentos iniciais defendidos quer pela Comissão, quer pelo Tribunal de Justiça se reconduziam à proteção da liberdade económica dos agentes de mercado e à prevenção de uso de poder económico em prejuízo de estruturas concorrenciais ${ }^{47}$ - ROSSI identifica o mercado interno como um objetivo fundamental, sem prejuízo de considerar que a defesa da concorrência constitui expressão da democracia económica e garante do cidadão para poder expressar o seu modo de vida e

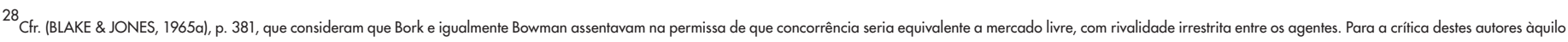

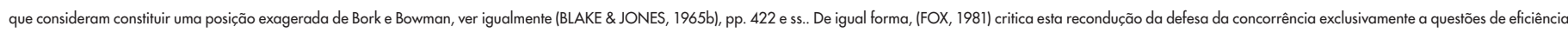

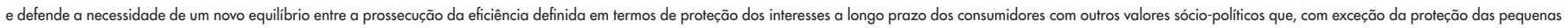
empresas, são compatíveis com o primeiro objetivo (pp. 1152-1153), utilizando um argumento que (ANDRIYCHUK, 2010), a pp. 575-576, também utilizará.

29 (EASTERBROOK, 1981), p. 266.

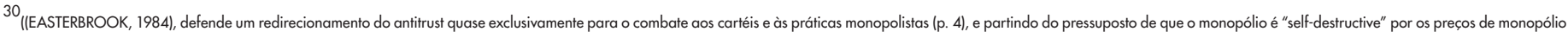
atraírem a entrada de novos concorrentes, preocupa-se apenas com o facto de tal poder apenas ocorrer no longo prazo, e daí considera que "The central purpose of antitrust is to speed up the arrival of the long run" (p. 2).

31

A questão, como bem (H. HOVENKAMP, 1986) coloca, é que não é seguro que os agentes económicos utilizem sempre essa racionalidade com o melhor propósito: "I agree heartily that the "desire to make a buck leads people to undermine monopolistic practices"; but the same desire leads people to undermine competitive practices as well." - p. 1728

32 (EASTERBROOK, 2000), p. 1, que eloquentemente refere que o direito da concorrência constitui um interessante instrumento apenas quando possui propósitos claros, porquanto de outra forma transforma-se em interferência aleatória na concorrência e prejudica os seus próprios objetivos.

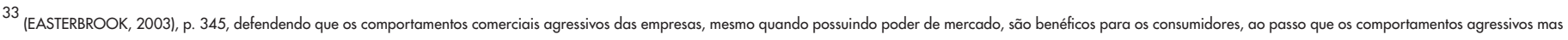
dotados de caráter ou propósito de exclusão são prejudiciais aos consumidores, sendo que "The big problem lies in this: competitive and exclusionary conduct look alike". Por outro lado, considera que os "False negatives take care of themselves as entry occurs. False positives should be -handled [... by] a wait-and-see attitude" (pp. 357-358).

${ }^{34}$ Ver ainda, e entre outros, (EASTERBROOK, 1982), pp. 708-709, (EASTERBROOK, 1983), p. 32, e (EASTERBROOK, 1987), p. 985

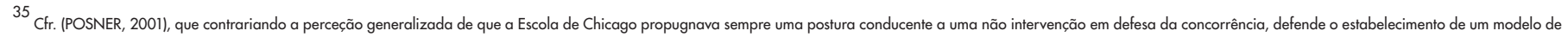

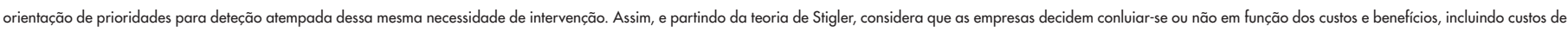
punição, pelo que defende ser possível identificar em que tipo de mercados é provável que seja tentada a colusão, podendo concentrar-se aí os recursos de investigação (pp. 68-69). 
DOI: 10.46294/ulplr-rdulp.siv 1 a4

bem-estar, assim ligando a concorrência à liberdade de escolha, e conclui que a defesa da concorrência "não é um modelo económico, mas sim um instrumento da liberdade dos cidadãos e pode e deve fazer parte de uma concepção de justiça baseada no pressuposto da propriedade privada ${ }^{\prime 48}$. SLOT defende que a inclusão de normas para a defesa da concorrência no Tratado CEE visou proteger e defender o objetivo primário do mesmo, ou seja, a integração do mercado 4950 . É esta proeminência, principal e duradoura, colocada naquele que consideram ser o objetivo primário do direito europeu da concorrência - defesa da integração do mercado - que leva a que CAYSEELE \& BERGH defendam que o mesmo apresenta caraterísticas distintas de outros direitos da concorrência, pela referida prevalência de preocupação com um objetivo de integração de mercados - objetivo esse que, por natureza e regra, estará ausente dos direitos nacionais de concorrência ${ }^{51}$ Essa é, portanto, uma perspetiva que simultaneamente colocará a tónica quer na estrutura, quer no processo concorrencial, que PERA reconduz à proteção do processo competitivo enquadrado na visão Ordoliberal ${ }^{52}$. Também GIFFORD \& KUDRLE sublinham a especificidade do direito europeu da concorrência, em parte porque o Tratado igualmente consagra valores "não-eficientes" a prosseguir ${ }^{53}$. GERBER também apresenta o direito europeu da concorrência como "especial" desde o seu início, por virtude do seu objetivo primário não ter vindo a ser o de obter os benefícios geralmente associados à concorrência, como sejam preços mais baixos para os consumidores ou o desenvolvimento tecnológico, mas sim 0 de atingir o específico objetivo de unificação do mercado europeu ${ }^{54}$. SULLIVAN \& FIKENTSCHER sustentam que apesar de sempre ter havido uma variedade de bens jurídicos ou objetivos da concorrência europeia, em que a eficiência é apenas um dentre outros, aquele respeitante à integração do mercado foi sempre mais forte, e que embora vá perdendo influência à medida do seu cumprimento, será de afastar que a eficiência se venha a tornar o único, ou mesmo o principal, objetivo do direito europeu da concorrência ${ }^{55}$

Por outro lado, e como PARRET já bem sublinhava - e aqui demonstrado, quando temos esta discussão pour cause da transposição da Diretiva $\mathrm{ECN}+-$, o recente processo de descentralização e decorrente acrescido enforcement do direito europeu da concorrência pelas autoridades nacionais de concorrência dos EM contribuiu para (re)iniciar a discussão sobre os objetivos do direito europeu da concorrência ${ }^{56}$. Seguramente que à medida que o mercado interno se vai aprofundando, se abrem "espaços" para (maior) consideração de outros valores, embora julguemos sensata a posição de LOWE \& HELD, que promovendo essa maior abertura a outros valores, fazem-se sempre "no âmbito" do mercado interno ${ }^{57}$. A tais argumentos acrescentamos ainda que haverá mesmo a necessidade de assim ser, por virtude do princípio do ne bis in idem, para não se prejudicar a aplicação cumulativa do direito europeu da concorrência com os direitos nacionais da concorrência. Para além de que não podemos deixar de atentar nas referências explícitas, nos tipos legais, à incompatibilidade com o mercado interno dos acordos entre empresas, decisões de associações de empresas e práticas concertadas que sejam susceptíveis de afectar o comércio entre os Estados-Membros e que tenham por objetivo ou efeito impedir, restringir ou falsear a concorrência no mercado interno, e à incompatibilidade com o mercado interno, na medida em que tal seja

${ }^{36}$ (POSNER, 1988), p. 890.

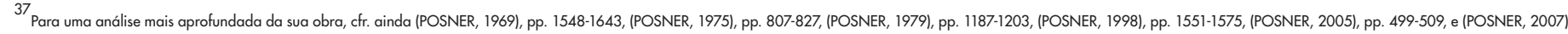
pp. 367-388. Para a crítica ao seu conceito de wealth maximization, ver (H. HOVENKAMP, 1990), pp. 825-826.

38

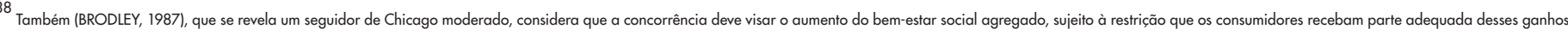
(p. 1023), utilizando, para isso, um conceito que denomina de "antitrust welfare".

39 (David J. GERBER, 2007), p. 720.

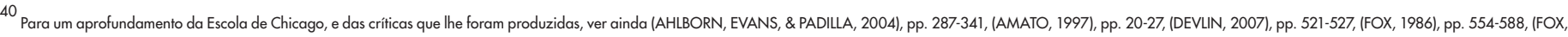
1987), pp. 917-922, (FOX \& PITOFSKY, 1987), pp. 931-935, (GERLA, 1996), pp. 210-223, (JONES \& SUFRIN, 2011), p. 22 e ss., (JOSKOW, 2002), pp. 103-104, (KAPLOW, 1987), pp. 181-216, (KAUPER, 2008), pp. 46-50, (KOVACIC, 2007), pp. 17-31, (LANDE, 1999), pp. 959-968, (LAVE, 2005), pp. 144-174, (LIEBELER, 1987), pp. 879-896, (MANNE \& WRIGHT, 2009), pp. 158-163, (MARKOVITS, 1984), pp. 41-87, (MCCHESNEY, 2009), pp. 11-31, (MILLON, 1988), pp. 1228-1231, (OLDHAM, 2007), pp. 340-343, (PAGE, 1989), pp. 1221-1308, (PAGE, 1995), pp. 42-47, (PAGE, 2009), p. 34, (PERA, 2008), pp. 137-140, (PERITZ, 1990), pp. 314-315, (PIRAINO, 2007), pp. 350-363, (SCHMALENSEE, 2008), pp. 11-23, (SCHMALENSEE, 1990), pp. 138-140, (SNYDER \& KAUPER, 1991), p. 551, (STEFANADIS, 1998), pp. 429-434, (SULLIVAN \& FIKENTSCHER, 1998), pp. 206-208, (TURNER, 1987), pp. 798-801, e (WILEY, 1987), pp. 587-589.

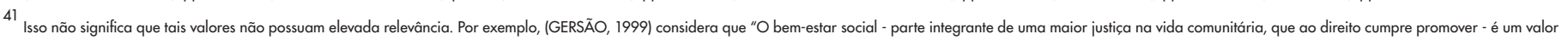
de nítido conteúdo ético." (pp. 91-92).

42 Considere-se também a possibilidade de realização de buscas domiciliárias prevista no art. 19. da LdC ou no art. 21. do Regulamento 1/2003. 
DOI: 10.46294/ulplr-rdulp.siv la4

susceptivel de afectar o comércio entre os Estados-Membros, o facto de uma ou mais empresas explorarem de forma abusiva uma posição dominante no mercado interno ou numa parte substancial deste - cfr. respetivamente os arts. 101. e 102. do TFUE.

Em cada um dos tipos é feita referência explícita e reiterada ao mercado interno, seja por emprego da própria expressão, seja por referência ao comércio entre EM, e a letra da lei identifica, assim, claramente qual o bem jurídico próprio que ao direito europeu da concorrência cumpre tutelar: o mercado interno. Não diremos que seja o único bem jurídico a tutelar, mas é seguramente o proeminente e próprio do direito europeu da concorrência, no sentido que não compete ao(s) direito(s) nacional(is) da concorrência defender o mercado interno ${ }^{58}$.

\subsection{A dignidade constitucional dos bens jurídicos protegidos pelo direito nacional da concorrência}

A defesa da concorrência constitui, em Portugal, um princípio fundamental e constitucionalmente consagrado, sendo assumida, na parte económica da Constituição da República Portuguesa (CRP), a subordinação do poder económico ao poder político democrático e a liberdade de iniciativa e de organização empresarial enquanto princípios fundamentais da organização económica-social do País (art. $80^{\circ}$, als. a) e c) da CRP). E enquanto incumbência prioritária do Estado é estabelecido o dever, entre outros, de assegurar o funcionamento eficiente dos mercados, de modo a garantir a equilibrada concorrência entre as empresas, a contrariar as formas de organização monopolistas e a reprimir os abusos de posição dominante e outras práticas lesivas do interesse geral (art. 81.․, al. fl da CRP).

Mas também o direito nacional da concorrência se apresenta como multivalor e podemos encontrar no DL n. ${ }^{\circ}$ 125/2014, de 18.08, pelo qual foram aprovados os atuais estatutos da $\mathrm{AdC}$ e cuja revisão igualmente se propugna em sede de transposição da Diretiva ECN+, a identificação da sua missão de "assegurar a aplicação das regras de promoção e defesa da concorrência [...] no respeito pelo princípio da economia de mercado e de livre concorrência, tendo em vista - funcionamento eficiente dos mercados, a afetação ótima dos recursos e os interesses dos consumidores ${ }^{\prime \prime 59}$.

Este é o resultado da evolução legislativa do direito nacional da concorrência, em que no primeiro regime jurídico da concorrência, estabelecido em 1983, era referido que a "defesa da concorrência constitui [...] um dos instrumentos essenciais da política económica, sendo-the comummente reconhecidas duas grandes virtualidades: a de garantir aos consumidores uma escolha diversificada de bens e serviços, nas melhores condições de qualidade e de preço, e a de estimular as empresas a racionalizar ao máximo a produção e a distribuição dos bens e serviços e a adaptarem-se constantemente ao progresso técnico e científico'60, no subsequente regime jurídico estabelecido no DL n. 371/93, visava-se dar "adequado cumprimento ao imperativo constitucional constante da alínea f) do artigo 81. da Constituição", e se reconhecia um quadro de integração dos "desenvolvimentos próprios de uma economia aberta, em crescente processo de internacionalização e de dinamismo concorrencial, contribuindo para a liberdade de formação da oferta e da procura e de acesso ao mercado, para o equilíbrio

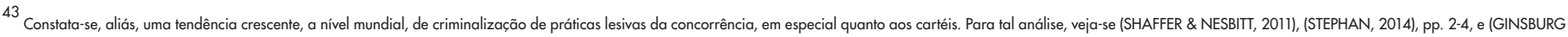
\& WRIGHT, 2010), pp. 22-29.

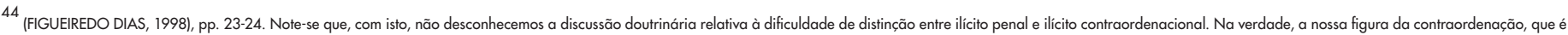

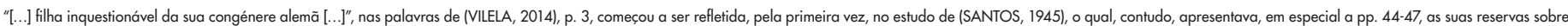

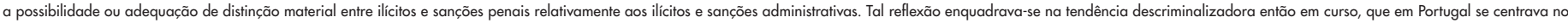

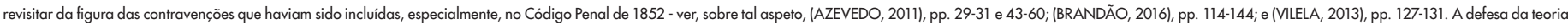

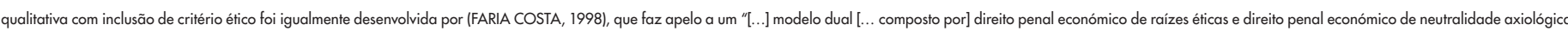

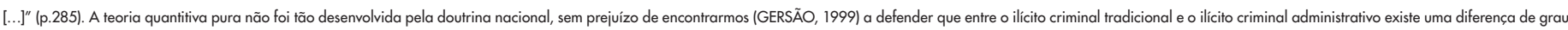

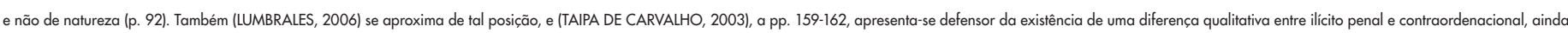

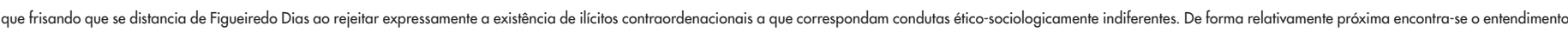

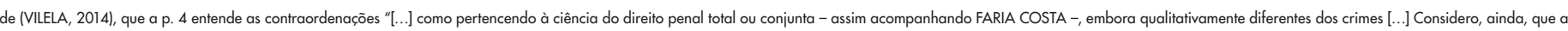

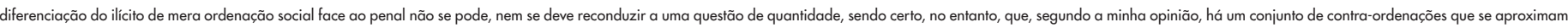
muito da ilicitude penal, porquanto protegem bens jurídicos com dignidade penal, relativamente aos quais não há necessidade de sanção penal, mas apenas de sanção contra-ordenacional."

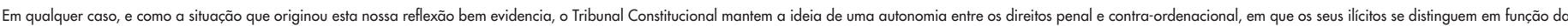
sua relevância ético-social (é um aliud em relação ao direito penal). 
DOI: 10.46294/ulplr-rdulp.siv 1 a4

das relações entre agentes económicos, para o favorecimento dos objectivos gerais de desenvolvimento económico e social, para o reforço da competitividade dos agentes económicos e para a salvaguarda dos interesses dos consumidores" ${ }^{61}$, e na posterior reforma de 2003, iniciada com o DL n. ${ }^{\circ} 10 / 2003$, se assumia que se pretendia que os agentes económicos pudessem "[...] dispor de um ordenamento concorrencial seguro e moderno, capaz de promover o funcionamento eficiente dos mercados, a repartição eficaz dos recursos nacionais e, sobretudo, a satisfação dos interesses dos consumidores" ${ }^{\prime \prime}$

Ou seja, a história legislativa nacional evidencia o referido caráter multivalor das normas nacionais de defesa da concorrência, e quando analisadas por referência ao comando constitucional que as conforma, legitima e baliza, podemos identificar como fundamentos políticos para a consagração de normas de defesa de concorrência razões relacionadas com o controlo do poder económico, com a salvaguarda da liberdade dos indivíduos e de empresa e a proteção dos consumidores.

No que respeita ao primeiro valor, note-se que o mesmo constitui já um bem jurídico reconhecido para outros delitos económicos - existência e manutenção da ordenação económica determinada pelo Estado -, mas que aqui surge na conformação típica da defesa da concorrência e consistente na preocupação de controlo do poder económico. Porquanto é disso mesmo que se trata: a defesa da concorrência constitui, em Portugal, um princípio fundamental e constitucionalmente consagrado, integrando-se no centro da constituição económica, a qual assenta, desde logo, no princípio de "subordinação do poder económico ao poder político democrático" (cfr. art. 80.', al. a) da CRP). E isto porque, como referem CANOTILHO \& MOREIRA, está aqui "a chave de toda a constituição económica", e em que se assume que o "poder económico só é subordinável ao poder político democrático desde que este o possa controlar", e para o que, de forma a "impedir preventivamente que o poder económico se venha a tornar incontrolável, a CRP estabelece, entre outras coisas, a exigência de eliminação de monopólios [...] - incumbindo o Estado de assegurar uma equilibrada concorrência entre as empresas (art. 81\% f) [...]" 6465 .

Por outro lado, as reiteradas preocupações com a atividade e a vida económica,

45 (GUERRIN \& KYRIAZIS, 1993), pp. 778-779.

46 (HARGITA \& TÓTH, 2005), p. 205.

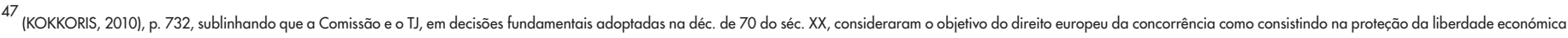
dos agentes, e não usaram conceitos económicos de bem-estar do consumidor.

48 (ROSSI, 1995), pp. 3, 7, 10-11 e 21.

49 (SLOT, 2004), p. 445.

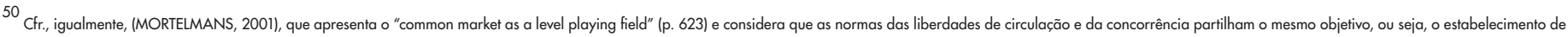
um mercado comum. Já (David J. GERBER, 2007), a p. 721, e para além de sublinhar a variedade de valores em defesa pelo direito europeu da concorrência, faz a ligação do controlo do poder económico à integração do mercado, considerando

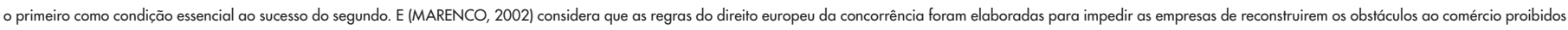
$\operatorname{aos} E M$.

51 (CAYSEELE \& BERGH, 2000), pp. 484-485.

52 Cfr. (PERA, 2008), p. 127. O autor sublinha a "ordoliberal view of competition" na qual o Tratado se funda e que assenta numa visão de "ensuring a free market economy in a free society", com o "competitive market system [...] placed at the

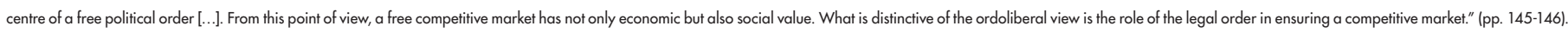

${ }^{53}$ Cfr. (GIFFORD \& KUDRLE, 2003), em particular a p. 779. E para uma súmula de parte da doutrina que critica a visão de recondução do direito europeu da concorrência apenas a postulados de proteção de eficiência ou de proteção de consumidores por considerar que o Tratado impõe ao direito europeu da concorrência a proteção de valores não necessariamente relacionados com eficiência, cfr. ainda (ODUDU, 2010), pp. 599-613.

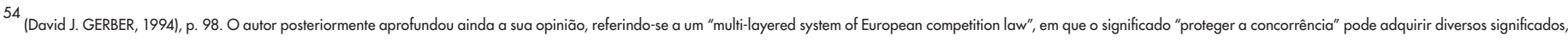
como sejam, proteger a eficiência económica, proteger a liberdade económica, ou controlar o poder económico enquanto necessidade de eliminação ou enfraquecimento de obstáculos à mudança económica ou ao desenvolvimento, mas em que na UE significa, igualmente, servir o objetivo da integração - cfr. (David J. GERBER, 2001), p. 124.

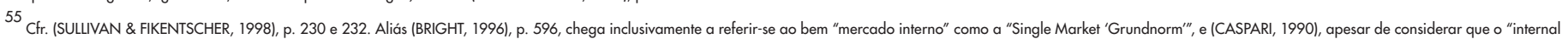
market is not an end in itself", suscitando assim a perspetiva política e mais abrangente da integração europeia, vai ao limite de "integrar" a política do mercado interno na política europeia de concorrência ("Internal market policy is [...] also

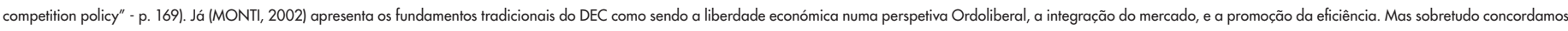

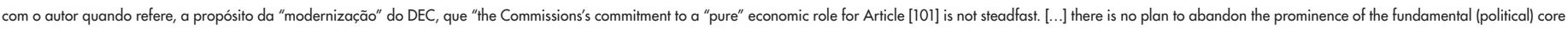
value: market integration." (cfr. p. 1091). 
DOI: 10.46294/ulplr-rdulp.siv 1 a4

próximos dos fundamentos económicos da concorrência quanto ao comportamento dos agentes económicos, sua rivalidade indutora de um processo concorrencial e numa estrutura de mercado que, assim, igualmente se revela benéfica, as mesmas são em grande medida reconduzíveis aos valores da liberdade dos indivíduos e de empresa (liberdades de ação, de decisão, de acesso ao mercado, de escolha). Na realidade, é assumida, na parte económica da CRP, a liberdade de iniciativa e de organização empresarial enquanto princípio fundamental da organização económica-social do País (cfr. art. 80., al. c) da CRP), que "reitera a garantia da liberdade de iniciativa económica estabelecida no art. $61^{\circ}$ - aqui acrescida da liberdade de organização empresarial [...]" ${ }^{\prime \prime}$. A este propósito, é aqui sublinhada esta dupla (mas cumulativa) perspetiva da liberdade individual e de empresa, mas a exegese conduz-nos a reconduzir a essência e razão de ser da liberdade à pessoa humana, tal qual os restantes direitos fundamentais ${ }^{67}$.

Estamos, portanto, centrados no valor fundamental, necessariamente erigível em bem jurídico, da liberdade da pessoa humana para agir e decidir, designadamente no campo económico, assim atuando quer no campo da oferta, quer no da procura de bens ou serviços. Ou a sua liberdade de escolha de profissão /cfr. art. $47^{\circ}$, n. $^{\circ} 1$ da CRP) que, não raras vezes, a conduzem a constituir-se na veste de agente económico e de empresa para efeito das normas de concorrência, e a sua liberdade de iniciativa económica privada (cfr. art. 61. ${ }^{\circ}$ n..$^{\circ} 1$ da CRP), designadamente originando pessoas coletivas para atuação e intervenção na atividade económica, acedendo e agindo em mercado(s). E porque the é reconhecida liberdade que a pessoa, singular ou coletiva, atua na vida económica, adoptando comportamentos, com maior ou menor rivalidade, e decidindo, por exemplo, diferenciar-se por inovação. Mas é também assente nessa liberdade que acede e intervem nos mercados, fomentando a existência e manutenção de uma estrutura concorrencial, pelo que a liberdade dos indivíduos e de empresa lde ação, de decisão, de acesso ao mercado, de escolhal se apresenta como conditio sine qua non para a existência de processos concorrenciais assentes em estruturas que, também elas, se pretendem tão concorrenciais quanto possível.

Ou seja, o próprio objetivo tradicionalmente atribuído à concorrência de geração de eficiência e maximização do bem-estar constituirá resultado expectável quer da existência e manutenção da ordenação económica determinada pelo Estado, ou seja do controlo do poder económico, quer da liberdade dos indivíduos e de

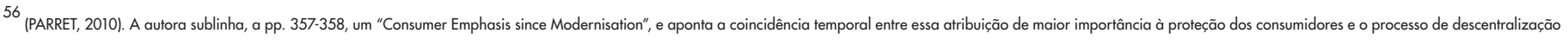
do direito europeu da concorrência.

57 (LOWE \& HELD, 2005), p. 35.

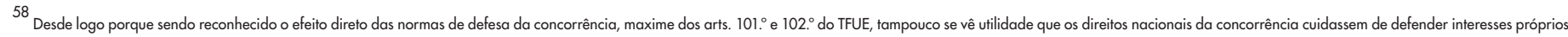
atribuídos à UE. E como (SILVA, 2009) refere a p. 106, "Nos casos em que nos situamos no âmbito estritamente nacional, há que, logo à partida, considerar que, no nosso ordenamento jurídico, a defesa da concorrência não está, nem nunca esteve ao serviço de objectivos como a integração ou o estabelecimento de um mercado único supra-nacional [...]". E desta forma, pela manutenção do valor mercado interno como bem jurídico principal do direito europeu da concorrência,

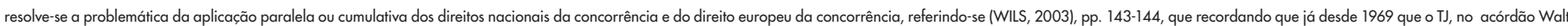

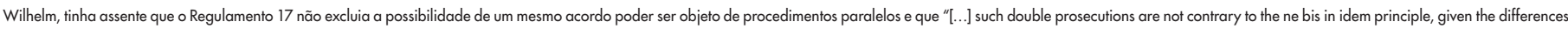
between the two laws, notably because Community law focuses on the effect on trade between Member States."

${ }^{59} \mathrm{Cfr}$. o . $^{\circ} 3$ do artigo $1 .^{\circ}$ dos estatutos da AdC, itálicos nossos.

${ }^{60} \mathrm{Cfr}$. o preâmbulo do DL n. ${ }^{4} 422 / 83$, itálicos nossos.

${ }^{61}$ Cfr. o preâmbulo do referido $\mathrm{DL}$ n. $371 / 93$, itálicos nossos

62 Em bom rigor, tal início da reforma remonta ao ano de 2002, tendo o DL n. . 10/2003 sido aprovado no seguimento da Lei de autorização n. ${ }^{\circ}$ 24/2002, de 31.10, que autorizava o Governo a criar uma Autoridade da Concorrência como autoridade independente - cfr. al. a) do artigo $2{ }^{\circ}$ da $\operatorname{Ln} .^{\circ} 24 / 2002$.

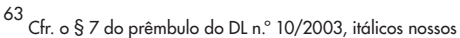

${ }^{64}$ Cfr. o $\$ 7$ do prêmbulo do DL n. ${ }^{\circ} 10 / 2003$, itálicos nossos

${ }^{65}$ No mesmo sentido, igualmente (MIRANDA \& MEDEIROS, 2006), p. 12

${ }^{66}$ (CANOTILHO \& MOREIRA, 2007), p. 958.

${ }^{67}$ No mesmo sentido, (ANASTÁCIO, 2010), p. 201.

${ }^{68}$ Disponível em https://www.parlamento.pt/ActividadeParlamentar/Paginas/Detalhelniciativa.aspx?:BID=110842

69 Já tivemos oportunidade de manifestar em (CASTRO MARQUES, 2019) a nossa absoluta discordância com a consideração de que os ilícitos jusconcorrências fossem dotados de neutralidade ou de menor desvalor ético-jurídico 
SPECIAL ISSUE I 2022

DOI: 10.46294/ulplr-rdulp.siv la4

empresa (de ação, de decisão, de acesso ao mercado, de escolha).

Nesta liberdade de atuação da pessoa, em particular da singular, poder-se-ia incluir também a sua liberdade como consumidor. Na verdade, o valor da proteção dos consumidores tem-se revelado um objetivo crescente da defesa da concorrência, mas o explícito reconhecimento constitucional do direito à proteção, designadamente, dos seus interesses económicos (cfr. art. 60. n n. 1 da CRP), fundamentará uma autonomização - e a própria dignidade - do bem a tutelar pelas normas de defesa da concorrência.

70

A circunstância de algo constituir um bem jurídico não significa ipse iure que seja um bem jurídico-penal, sê-lo-á apenas se passar os crivos cumulativos da dignidade penal, da necessidade ou carência de tutela penal, e da natureza subsidiária desta enquanto ultima ratio. Nesse sentido, ver, p. ex., (FIGUEIREDO DIAS, 2004), pp. 120-121, e (TAIPA DE CARVALHO, 2003), pp. 65-66.

71

Em rigor, não será somente esse o problema, como bem o demonstra o recente Acórdão n. $687 / 2021$ do Tribunal Constitucional e que em apreciação do artigo $5 .^{\circ}$ do Decreto n. $167 /$ XIV da Assembleia da República, que alterava o artigo

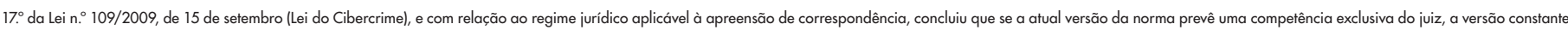

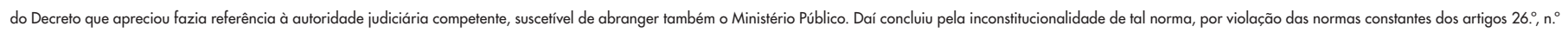
$1,344^{\circ}, n^{\circ} 1,35^{\circ}$, n. s 1 e 4, 32. , n. 4, e 18. , n. 2, da Constituição da República Portuguesa, por da mesma resultar quer uma restrição dos direitos fundamentais à inviolabilidade da correspondência e das comunicações e à proteção dos

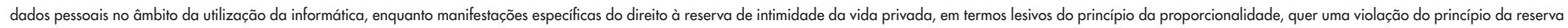
de juiz e das garantias constitucionais de defesa em processo penal.

72 (MIRANDA \& MEDEIROS, 2006), p. 20.

73 (FIGUEIREDO DIAS, 1998), pp. 23-24.

74 (FARIA COSTA, 2004), pp. 30-32.

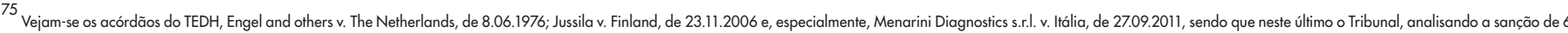
milhões de euros aplicada pela autoridade nacional de concorrência italiana à empresa por participação em cartel, considerou que mau grado não ser qualificada no direito italiano como infração penal, a mesma, atenta a sua severidade e

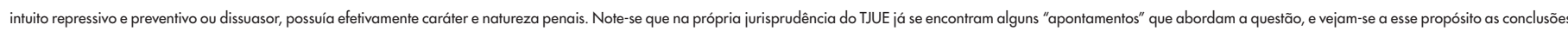
do Juiz Vesterdorf, agindo como Advogado-Geral, no caso T-1/89 Rhône Poulenc SA c. Comissão, e nas quais era claramente defendido a p. 885 que "[i]n view of the fact [...] that fines which may be imposed on undertakings pursuant to Article

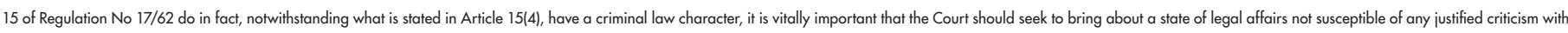
reference to the European Convention for the Protection of Human Rights.", ou ainda as conclusões do Advogado-Geral léger no caso C-185/95 P Baustahlgwebe c. Comissão, e onde foi igualmente considerado no § 31 que "É pacífico, e a Comissão também não contesta que, à luz da jurisprudência do [TEDH], bem como dos pareceres da Comissão Europeia dos Direitos do Homem, o presente processo se enquadra no âmbito da "matéria penal".

${ }^{76}$ Também em sede de discussão doutrinal a questão da natureza das sanções aplicadas por violação do direito europeu da concorrência se vem colocando com crescente acuidade. (BRONCKERS \& VALLERY, 2011), pp. 548-556, criticam o potencial impacto sobre direitos fundamentais e decorrente da Comissão assumir diferentes funções ("investigator, prosecutor, adjudicator, and policymaker"); (PIERNAS LÓPEZ, 2006), pp. 447-448, considera que "[...] the distinction between

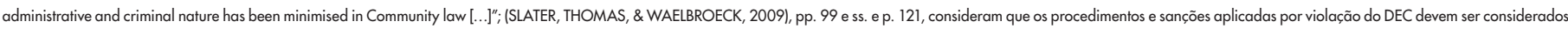

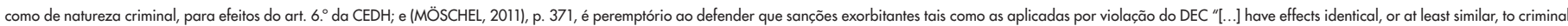
sanctions. Any other perception would be a life lie."

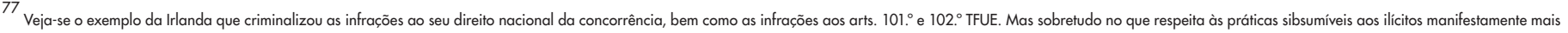
graves, como sejam os cartéis e o bid-rigging, constata-se uma tendência para a sua criminalização, designadamente em Estados-Membros com tradição jurídica relevante para o nosso ordenamento, a saber, na França e na Alemanha. No caso francês, a criminalização dos cartéis remonta ao art. 419 do Código Penal francês, e tal natureza sancionatória de natureza penal mantem-se, atualmente à luz do art. L420-6 do Code de commerce. Já no caso alemão, a tutela penal para as situações de bid rigging surge na secção 298 do Código Penal alemão.

Já no anterior Regulamento 17/62, quer no atual Regulamento 1/2003, relativo à execução das regras de concorrência estabelecidas nos artigos $101 .^{\circ}$ e $102 .^{\circ}$ do TFUE, se estatui que as decisões condenatórias ao abrigo do direito europeu da concorrência "não [possuem] natureza penal". 


\section{Retome-se o sentido das palavras ... o texto constitucional como quadro de referência delimitador da atividade punitiva do Estado}

Recorde-se o problema e retome-se o sentido das palavras.

O problema. Como bem se refere na Nota Técnica dos serviços da Assembleia da República ${ }^{68}$, as infrações sancionadas pelo regime jurídico da concorrência correspondem a ilícitos contraordenacionais, considerados associados a um menor desvalor ético-jurídico face aos ilícitos criminais e assentes em procedimentos não tão garantísticos quanto aqueles estabelecidos nos direitos penal e processual penal ${ }^{69}$. Como é óbvio, ou visto no prisma diametralmente correspondente, é por tanto que as ingerências e diligências das autoridades públicas mais impactantes nos direitos fundamentais das pessoas se encontram reservadas aos processos penais, porque aí se tutelam bens jurídicos com maior valor ético-jurídico e se - faz através de procedimentos garantísticos e escrutinados. E é precisamente nesse campo do equilíbrio entre a tutela dos bens jurídicos com dignidade penal ${ }^{70}$ e as garantias do processo criminal estabelecidas no art. $32 .^{\circ}$ da CRP, que o art. 34. ${ }^{\circ}$ da CRP, relativo à inviolabilidade do domicílio e da correspondência, determina que a entrada no domicílio dos cidadãos contra a sua vontade só pode ser ordenada pela autoridade judicial competente, nos casos e segundo as formas previstos na lei e que, no que aqui mais proximamente nos cuida, é proibida toda a ingerência das autoridades públicas na correspondência, nas telecomunicações e nos demais meios de comunicação, salvos os casos previstos na lei em matéria de processo criminal ${ }^{71}$.

Então o "problema" é, tão simplesmente, ter-se previsto a possibilidade de ingerência na correspondência, nas telecomunicações e nos demais meios de comunicação em processo contraordenacional, e não em processo criminal

E o sentido das palavras. É que o caráter sancionatório do direito nacional da concorrência constitui uma marca indelével e integrante do próprio comando constitucional de defesa da concorrência.

A al. fl do art. 81. da CRP, para além de determinar a incumbência prioritária do Estado em "assegurar o funcionamento eficiente dos mercados, de modo a garantir a equilibrada concorrência entre as empresas", enquanto obrigação de prossecução de um "[...] valor objectivo-positivo de organização económica, ou seja, como garantia-institucional da ordem económica" ${ }^{72}$, foi ainda mais longe e estabeleceu o poder-dever do Estado de "reprimir os abusos de posição dominante e outras práticas lesivas do interesse geral" (sublinhado nosso).

Tal referência explícita, na letra constitucional, à incumbência de repressão de práticas lesivas da concorrência preenche, desde logo, o aspeto fundamental de cumprir o "quadro de referência" que constitui o "critério regulativo e delimitativo do âmbito de uma aceitável e necessária actividade punitiva do Estado" 73

Concorda-se que se impõe um cuidado de permanente verificação de atualidade na aplicação desta teoria da vinculação constitucional dos bens jurídico-penais, que estabelece a necessidade "[...] de analogia material, fundada numa essencial correspondência de sentido e - do ponto de vista da sua tutela - de fins. Correspondência que deriva [...] de a ordem jurídico-constitucional constituir o quadro obrigatório de referência e, ao mesmo tempo, o critério regulativo da actividade punitiva do Estado.", mas que obriga a que se reconheça que "[...] a passagem do tempo tem transportado consigo algum desconforto para tal construção teórica. Como nota Gomes Canotilho, aquela pirâmide jurídica [com a Constituição no vértice] não possui já "virtualidades suficientes para captar o relevo jurídico do direito internacional e do direito comunitário" [...]", bem como que se atente que "A necessidade de encontrar um arrimo constitucional para a eleição dos bens jurídico-penais pode, ainda, vir a revelar-se uma limitação inaceitável sempre que a Constituição deixe de estar exactamente coincidente ou quase coincidente com o espírito dos tempos." ${ }^{74}$

Porém, in casu podemos trabalhar com a plenitude teoria da vinculação constitucional dos bens jurídico-penais, porquanto inexiste um qualquer risco de não arrimo constitucional no campo da defesa da concorrência, onde se vem assistindo - e a Diretiva ECN+ e consequente Proposta de Lei n. $99 / \mathrm{XIV} / 2$. $^{a}$ para sua transposição bem o evidenciam - a um constante aumento, no direitos nacional e europeu da concorrência, do seu caráter sancionatório.

Ou seja, neste particular aspeto do caráter repressivo a atribuir às normas de defesa da concorrência - ou, dito de outra forma, a proteção dos bens jurídicos tutelados através de normas com natureza sancionatória -, há um alinhamento que diríamos quase perfeito entre a opção constitucional de reprimir as práticas lesivas da concorrência e o espírito dos tempos. Um espírito dos tempos marcado por uma tendência da UE e os seus Estados-Membros de dar cada vez mais corpo a esse caráter repressivo, e onde a Diretiva ECN+, com o propósito de aumentar a eficácia na aplicação das normas de defesa da concorrência, designadamente com o reconhecimento de competências inspetivas e meios de investigação suficientes harmonização dos meios de prova admissíveis e competências sancionatórias e a harmonização dos programas de clemência em caso de cartéis, se insere. Mas dizemos que esse alinhamento é quase perfeito, não fora o "problema". E o problema é, na verdade, o de sempre.

O de se pretender, por um lado, continuar a "ignorar" que a União Europeia não 
SPECIAL ISSUE I 2022

DOI: $10.46294 /$ ulplr-rdulp.siv la4

possui competências penais mas que, paradoxalmente, vem construindo um registo de aplicação de sanções em sede de direito da concorrência que já conduziu o Tribunal Europeu dos Direitos Humanos a concluir pela sua subsunção ao artigo 6. da Convenção Europeia dos Direitos do Homem, que estabelece o conteúdo garantístico mínimo para um processo equitativo, mormente em matéria penal. ${ }^{7576}$. E o de, por outro lado, se manter no nosso ordenamento jurídico a natureza (formalmente) contraordenacional das sanções por ilícitos jusconcorrenciais. E isto quando, como visto e pelo menos no que respeita às práticas mais graves, como sejam os cartéis, se poder sustentar que a referência constitucional e os bens jurídicos tutelados permitem, como visto, que o legislador infraconstitucional adequasse a melhor natureza jurídica a atribuir à atividade sancionatória dos diferentes ilícitos tipificados.

Ou seja, o suporte constitucional à "repressão" de práticas lesivas da concorrência é substancial e insere-se de forma clara na atividade punitiva do Estado, a qual poderá, sempre que adequado e necessário, assentar no recurso à ultima ratio, ou seja, ao direito e sanções de natureza criminal ${ }^{77}$.

Enquanto não se abordar de forma clara e direta tal problema, continuaremos seguramente a assistir a espantosas situações, como quando em transposição de uma Diretiva da União Europeia e no âmbito de um direito e sanções pretensamente de natureza administrativa ${ }^{78}$, se viola a proibição constitucional de ingerência, ressalvadas as exceções previstas em sede de processo criminal, na correspondência, nas telecomunicações e nos demais meios de comunicação. 


\section{Bibliografia}

AHLBORN, C., EVANS, D. S., \& PADILLA, A. J. (2004). The antitrust economics of tying: a farewell to per se illegality. The Antitrust Bulletin, Spring-Summer, 287-341. ALMEIDA, Á. (2007). Economia Aplicada para Gestores (2ª Edição ed.). V. N. Gaia: Espaço Atlântico.

AMATO, G. (1997). Antitrust and the Bounds of Power - The Dilemma of Liberal Democracy in the History of the Market. Oxford: Hart Publishing.

ANASTÁCIO, C. (2010). O dever de colaboração no âmbito dos processos de contra-ordenação por infracção às regras de defesa da concorrência e o princípio nemo tenetur se ipsum accusare. Revista de Concorrência e Regulação, Ano I(n. . 1), pp. 199-235.

ANDRIYCHUK, O. (2010). Rediscovering the Spirit of Competition: On the Normative Value of the Competitive Process. European Competition Journal, 6(3), 575-610.

ANDRIYCHUK, O. (2012). The Dialectics of Competition Law: Sketching the Ordo-Austrian Approach to Antitrust. World Competition, 35(2), $355-384$.

AZEVEDO, T. L. d. (2011). Da subsidiariedade no direito das contra-ordenações: problemas, críticas e sugestões práticas. Coimbra: Coimbra Editora.

BLAKE, H. M., \& JONES, W. K. (1965a). In Defense of Antitrust. Columbia Law Review, 65(3), 377-400.

BLAKE, H. M., \& JONES, W. K. (1965b). Toward a Three-Dimensional Antitrust Policy. Columbia Law Review, 65(3), 422-466.

BORK, R. H. (1965a). Contrasts in Antitrust Theory: I. Columbia Law Review, 65(3), 401-416.

BORK, R. H. (1965b). The Rule of Reason and the Per Se Concept: Price Fixing and Market Division. Yale Law Journal, 74(5), 775-847.

BORK, R. H. (1966a). Legislative Intent and the Policy of the Sherman Act. Journal of Law and Economics, IX, 7-48.

BORK, R. H. (1966b). The Rule of Reason and the Per Se Concept: Price Fixing and Market Division. Yale Law Journal, 75(3), 373-475.

BORK, R. H. (1967). The Goals of Antitrust Policy. American Economic Review (Papers and Proceedings), 57(2), $242-253$.

BORK, R. H., \& BOWMAN, W. (1965). The Crisis in Antitrust. Columbia Law Review, 65(3), 363-376.

BOWMAN, W. (1965). Contrasts in Antitrust Theory: II. Columbia Law Review, 65(3), 417-421.

BRANDÃO, N. (2016). Crimes e contra-ordenações: da cisão à convergência material - ensaio para uma recompreensão da relação entre o direito penal e o direito contra-ordenacional. Coimbra: Coimbra Editora.

BRIGHT, C. (1996). EU Competition Policy: Rules, Objectives and Deregulation. Oxford Journal of Legal Studies, 16(4), 535.

BRODLEY, J. F. (1987). The Economic Goals of Antitrust: Efficiency, Consumer Welfare, and Technological Progress. New York University Law Review, 62(5), 1020.

BRONCKERS, M. C. E. J., \& VAlLERY, A. (2011). No Longer Presumed Guilty? The Impact of Fundamental Rights on Certain Dogmas of EU Competition Law. World Competition, 34(4), 535-570

CAEIRO, P. (1998). Perspectivas de formação de um direito penal da União Europeia. In Direito Penal Económico e Europeu: Textos Doutrinários (Vol. Volume I, pp. 519532). Coimbra: Coimbra Editora.

CAMPOS, J. M. d., \& CAMPOS, J. L. M. d. (2010). Manual de Direito Europeu (6 edição ed.). Coimbra: Wolters Luwer Portugal - Coimbra Editora

CANOtIllHO, J. J. G., \& MOREIRA, V. (2007). Constituição da República Portuguesa Anotada (Vol. Volume I- Artigos $1^{\circ}$ a 107%. Coimbra: Coimbra Editora.

CASPARI, M. (1990). 1992 -- EEC Competition Law and Industrial Policy. Fordham Corp. L. Inst., 1989 (B. Hawk, org., 1990), 163-180.

CASTRO MARQUES, N. (2019). Contributo para a Autonomia do Direito Nacional da Concorrência - em particular na criminalização dos cartéis Porto: Universidade Católica Editora.

CAYSEELE, P. V., \& BERGH, R. J. V. d. (2000). Antitrust Law. In B. BOUCKAERT \& G. DE GEEST (Eds.), Encyclopedia of Law and Economics (Vol. Vol. III, The Regulation of Contracts, pp. 467-497). Cheltenham: Edward Elgar Publ.

DENIS, H. (2000). História do Pensamento Económico (P. U. d. France Ed. $8^{a}$ edição ed.). Lisboa: Livros Horizonte (edição portuguesa)

DEVLIN, A. (2007). A Neo-Chicago perspective on the law of product tying. American Business Law Journal, 44(Fall).

EASTERBROOK, F. H. (1981). Predatory Strategies and Counterstrategies. University of Chicago Law Review, 48, 263.

EASTERBROOK, F. H. (1982). Is There a Ratchet in Antitrust Law? Texas Law Review, 60, 705.

EASTERBROOK, F. H. (1983). Antitrust and the Economics of Federalism. Journal of Law and Economics, XXVIII), 23.

EASTERBROOK, F. H. (1984). The Limits of Antitrust. Texas Law Review, 63(1), 1.

EASTERBROOK, F. H. (1987). Comparative Advantage and Antitrust Law. California Law Review, 75(3), 983. 
EASTERBROOK, F. H. (2000). Information and Antitrust. University of Chicago Legal Forum, 1.

EASTERBROOK, F. H. (2003). When is it Worthwhile to use Courts to Search for Exclusionary Conduct. Columbia Business Law Review(2), 345.

ETTER, B. (2000). The Assessment of Mergers in the EC under the Concept of Collective Dominance. An Analysis of the Recent Decisions and Judgments-by an Economic Approach. World Competition, 23(3), 103-139.

FARIA COSTA, J. d. (1998). Breves reflexões sobre o Decreto-lei n. 2 207-B/75 e o direito penal económico. In Direito Penal Económico e Europeu: Textos Doutrinários (Vol. Volume I, pp. 277-292). Coimbra: Coimbra Editora.

FARIA COSTA, J. d. (2004). Direito Penal Especial (Contributo a uma sistematização dos problemas "especiais" da parte especial). Coimbra: Coimbra Editora. FIGUEIREDO DIAS, J. d. (1998). O Movimento de Descriminalização e o llícito de Mera Ordenação Social. Direito Penal Económico e Europeu: Textos Doutrinários, Vol. I- Problemas Gerais, pp. 19-33.

FIGUEIREDO DIAS, J. d. (2004). Direito Penal - Parte Geral - Tomo I - Questões Fundamentais. A Doutrina Geral do Crime. Coimbra: Coimbra Editora.

FIGUEIREDO DIAS, J. d., \& COSTA ANDRADE, M. d. (1999). Sobre os crimes de fraude na obtenção de subsídio ou subvenção e de desvio de subvenção, subsídio ou crédito bonificado. In Direito Penal Económico e Europeu: Textos Doutrinários (Vol. Volume II, pp. 321-345). Coimbra: Coimbra Editora.

FOX, E. M. (1981). The Modernization of Antitrust: A New Equilibrium. Cornell Law Review, 66(6), 1140.

FOX, E. M. (1986). The Politics of Law and Economics in Judicial Decision Making: Antitrust as a Window. New York University Law Review, 61(4), 554.

FOX, E. M. (1987). The Battle for the Soul of Antitrust. California Law Review, 75(3), 917.

FOX, E. M., \& PITOFSKY, R. (1987). The Antitrust Alternative - Introduction. New York University Law Review, 62(5), 931.

GERBER, D. J. (1994). The Transformation of European Community Competition Law. Harvard International Law Journal, 35(1), 97-147.

GERBER, D. J. (2001). Modernising European Competition Law: A Developmental Perspective. European Competition Law Review, 22(4), 122-130.

GERBER, D. J. (2007). Competition law and the WTO: rethinking the relationship. Journal of International Economic Law, 10(3), $707-724$.

GERLA, H. S. (1996). Restoring Rivalry As a Central Concept in Antitrust Law. Nebraska Law Review, 75(2), $209-254$.

GERSÃO, E. (1999). Revisão do sistema jurídico relativo à infracção fiscal. In Direito Penal Económico e Europeu: Textos Doutrinários (Vol. Volume II, pp. 85-99). Coimbra: Coimbra Editora.

GIFFORD, D. J., \& KUDRLE, R. T. (2003). European Union competition law and policy: how much latitude for convergence with the United States? Antitrust Bulletin, 48(2), 727-780.

GIFFORD, D. J., \& SULLIVAN, E. T. (2007). The Roberts antitrust court: A transformative beginning. Antitrust Bulletin, 62(3-4), 435

GINSBURG, D. H., \&WRIGHT, J. D. (2010). Antitrust Sanctions. Competition Policy International, 6(2), 3-39.

GORJÃO-HENRIQUES, M. (2019). Direito da União: História, Direito, Cidadania, Mercado Interno e Concorrência (9ª edição ed.). Coimbra: Almedina.

GORJÃO-HENRIQUES, M., \& SAAVEDRA, A. (2020). Directiva ECN+ e a Nova Era do Direito da Concorrência (Desafios e Limites). Revista da Ordem dos Advogados, 80(Jan./Jun. 2020), 219-256.

GRAUER, M. C. (1989). The Use and Misuse of the Term 'Consumer Welfare': Once More to the Mat on the Issue of Single Identity Status for Sports Leagues Under Section 1 of the Sherman Act. Tulane Law Review, 64(1), 71.

GUERRIN, M., \& KYRIAZIS, G. (1993). Cartels: Proof and Procedural Issues. Fordham Corp. L. Inst., 1992 (B. Hawk, org., 1993), $773-843$.

HARGITA, Á., \& TÓTH, T. (2005). God Forbid Bid-Riggers: Developments under the Hungarian Competition Act. World Competition, 28(2), $205-231$.

HILDEBRAND, D. (2002). The European School in EC Competition Law. World Competition, 25(1), 3-23.

HOVENKAMP, H. (1985). Antitrust Policy after Chicago. Michigan Law Review, 84(2), 213.

HOVENKAMP, H. (1986). Rethoric and Skepticism in Antitrust Argument. Michigan Law Review, 84(8), 1721.

HOVENKAMP, H. (1990). Positivism in Law and Economics. California Law Review, 78(4), 815.

HOVENKAMP, H. (2005). The Antitrust Enterprise - Principle and Execution. Cambridge, Massachusetts: Harvard Univ. Press.

HOVENKAMP, H. J. (2007). The Harvard and Chicago Schools and the Dominant Firm. The University of lowa Legal Studies Research Paper No. 07-19. SSRN.

JONES, A., \& SUFRIN, B. (2011). EU Competition Law - Text, Cases, and Materials (4th edition ed.). New York: Oxford University Press.

JOSKOW, P. L. (2002). Transaction Cost Economics, Antitrust Rules, and Remedies. Journal of Law, Economics and Organization, 18(1), 95-116. 
KAPLOW, L. (1987). Antitrust, Law \& Economics, and the Courts. Law and Contemporary Problems, 50(4), 181-216.

KAUPER, T. E. (2008). Influence of Conservative Economic Analysis on the Development of the Law of Antitrust. In R. PITOFSKY (Ed.), How the Chicago School Overshot the Mark (pp. 40-50). Oxford: Oxford Univ. Press.

KOKKORIS, I. (2010). Should crisis cartels exist amid crises? Antitrust Bulletin, 55(4), 727.

KOVACIC, W. E. (2007). The intellectual DNA of modern U.S. competition law for dominant firm conduct: the Chicago/Harvard double helix. Columbia Business Law Review, 1-80.

LANDE, R. H. (1999). Proving the Obvious: The Antitrust Laws Were Passed to Protect Consumers (Not Just to Increase Efficiency). Hastings Law Journal, $50(4), 959-968$. Retrieved from http://home.ubalt.edu/ntlaland

LAVE, J. M. (2005). The law and economics of de facto exclusive dealing. The Antitrust Bulletin, 50, n 1(Spring), 143-180.

LIEBELER, W. J. (1987). What are the Alternatives to Chicago? Duke Law Journal, 36(7), 879.

LOWE, P., \& HELD, A. (2005). Modernisation and Beyond: The Role of Competition Policy in Driving Economic Growth. European Competition Journal, 1(1), 35

LUMBRALES, N. B. M. (2006). Sobre o Conceito Material de Contra-Ordenação. Lisboa: Universidade Católica Editora.

MANNE, G. A., \& WRIGHT, J. D. (2009). Innovation and the Limits of Antitrust. Journal of Competition Law and Economics, 6(1), $153-202$.

MARKOVITS, R. S. (1984). The Limits to Simplifying Antitrust: A Reply to Professor Easterbrook. Texas Law Review, 63(1), 41-87.

MARTINS, A. M. G. (2012). Manual de Direito da União Europeia. Coimbra: Almedina.

MARTINS, P. F. (2012). Princípio das Competências Atribuídas e Princípio das Competências Implícitas. In S. d. O. PAIS (Ed.), Princípios Fundamentais de Direito da União Europeia - Uma Abordagem Jurisprudencial (2ª ed., pp. 153-176). Coimbra: Almedina.

MCCHESNEY, F. S. (2009). Easterbrook on Errors. Journal of Competition Law and Economics, 6(1), 11-31.

MCNULTY, P. J. (1967). A Note on the History of Perfect Competition. Journal of Political Economy, 75(4), 395-399.

MILLON, D. (1988). The Sherman Act and the Balance of Power. Southern California Law Review, 61(5), 1293.

MIRANDA, J., \& MEDEIROS, R. (2006). Constituição Portuguesa Anotada - Tomo II. Coimbra: Coimbra Editora.

MORTELMANS, K. J. M. (2001). Towards Convergence in the Application of the Rules on Free Movement and Competition? Common Market Law Review, 38(3), 613649.

MÖSCHEL, W. (2011). Fines in European competition law. European Competition Law Review, 32(7).

ODUDU, O. (2010). The Wider Concerns of Competition Law. Oxford Journal of Legal Studies, 30(3), 599-613.

OLDHAM, A. S. (2007). Sherman's march (in)to the sea. Tennessee Law Review(Spring).

PAGE, W. H. (1989). The Chicago School and the Evolution of Antitrust: Characterization, Antitrust Injury, and Evidentiary Sufficiency. Virginia Law Review, 75(7), 12211308.

PAGE, W. H. (1995). Legal Realism and the Shaping of Modern Antitrust. Emory Law Journal, 44(1), 1-70.

PAGE, W. H. (2009). Microsoft and the Limits of Antitrust. Journal of Competition Law and Economics, 6(1), 33-50.

PARRET, L. (2010). Shouldn't We Know What We are Protecting? Yes We Should! A Plea for a Solid and Comprehensive Debate about the Objectives of EU Competition Law and Policy. European Competition Journal, 6(2), 339-376.

PERA, A. (2008). Changing Views of Competition, Economic Analysis and EC Antitrust Law. European Competition Journal, 4(1), 127-168.

PERITZ, R. J. R. (1990). A Counter-History of Antitrust Law. Duke Law Journal, 39(2), 263.

PIERNAS LÓPEZ, J. J. (2006). The Aggravating Circumstance of Recidivism and the Principle of Legality in the EC Fining Policy: Nulla Poena Sine Lege? World Competition, 29(3), 441.

PIRAINO, T. A., Jr. (2007). Reconciling the Harvard and Chicago Schools: a new antitrust approach for the 21 st century. Indiana Law Journal, 82(Spring), $345-409$.

POSNER, R. A. (1969). Oligopoly and the Antitrust Laws: A Suggested Approach. Stanford Law Review, 21(6), 1548-1643.

POSNER, R. A. (1975). The Social Costs of Monopoly and Regulation. Journal of Political Economy, 83(4), 807-827.

POSNER, R. A. (1979). Information and Antitrust: Reflections on the Gypsum and Engineers Decisions. Georgetown Law Journal, 67, $1187-1203$.

POSNER, R. A. (1988). The Jurisprudence of Skepticism. Michigan Law Review, 86(5), 827. 
DOI: 10.46294/ulplr-rdulp.siv la4

POSNER, R. A. (1998). Rational Choice, Behavioral Economics, and the Law. Stanford Law Review, 50(5), 1551-1575.

POSNER, R. A. (2001). Antitrust Law - An Economic Perspective (2ª ed.). Chicago: Chicago Univ. Press.

POSNER, R. A. (2005). Keynote address: Vertical restrictions and "fragile" monopoly. The Antitrust Bulletin, 50, n 3(Fall), $499-509$.

POSNER, R. A. (2007). Economic Analysis of Law (7. ed.). New York: Aspen Publishers.

ROSSI, G. (1995). Antitrust e teoria della giustizia. Rivista delle società, 40(1), 1-21.

SANTOS, B. D. (1945). Ilícito Penal Administrativo e llícito Criminal. Revista da Ordem dos Advogados, I/II, 39-59.

SCHMALENSEE, R. (1990). Empirical Studies of Rivalrous Behaviour. In G. BONNANNO \& D. BRANDOLINI (Eds.), Industrial Structure in the New Industrial Economics (pp. 138-167). Oxford: Clarendon Press.

SCHMALENSEE, R. (2008). Thoughts on the Chicago Legacy in U.S. Antitrust. In R. PITOFSKY (Ed.), How the Chicago School Overshot the Mark - The Effect of Conservative Economic Analysis on U.S. Antitrust (pp. 11-23). New York: Oxford University Press.

SCHUMPETER, J. A. (1976). Capitalism, Socialism and Democracy (5. ${ }^{a}$ ed.). Londres: Routledge.

SHAFFER, G. C., \& NESBITT, N. H. (2011). Criminalizing Cartels: A Global Trend? Legal Studies Research Paper Series.

SIIVA, F. R. (2009). Um Olhar "Comercial" Sobre o Direito Contra-Ordenacional. Julgar(8), 101-117.

SLATER, D., THOMAS, S., \& WAELBROECK, D. (2009). Competition Law Proceedings before the European Commission and the Right to a Fair Trial: No Need for Reform? European Competition Journal, 5(1), 97-143.

SLOT, P. J. (2004). A view from the mountain: 40 years of developments in EC competition law. Common Market Law Review, 41(2), $443-473$.

SNYDER, E. A., \& KAUPER, T. E. (1991). Misuse of the Antitrust Laws: The Competitor Plaintiff. Michigan Law Review, 90(3), $551-603$.

STEFANADIS, C. (1998). Selective Contracts, Foreclosure, and the Chicago School View. Journal of Law and Economics, 41(2), $429-450$.

STEPHAN, A. (2014). Four Key Challenges to the Successful Criminalization of Cartel Laws. Journal of Antitrust Enforcement, 1-30.

STIGLER, G. J. (1957). Perfect Competition, Historically Contemplated. Journal of Political Economy, 65(1), 1-17.

SULLIVAN, E. T., \& FIKENTSCHER, W. (1998). On the Growth of the Antitrust Idea. Berkeley Journal of International Law, 16, $197-233$.

TAIPA DE CARVALHO, A. A. (2003). Direito Penal - Parte Geral. Questões Fundamentais. Porto: Publicações Universidade Católica.

TURNER, D. F. (1987). The Durability, Relevance, and Future of American Antitrust Policy. California Law Review, 75(3), 797.

VATIERO, M. (2010). The Ordoliberal Notion of Market Power: An Institutionalist Reassessment. European Competition Journal, 6(3), 689.

VILELA, A. (2013). O Direito de Mera Ordenação Social: Entre a Ideia de "Recorrência" e a de "Erosão" do Direito Penal Clássico. Coimbra: Coimbra Editora.

VILELA, A. (2014). A Segunda parte do regime geral do ilícito de mera ordenação social: um direito processual muitas vezes ignorado. Revista da Faculdade de Direito da Universidade Lusófona do Porto, 4, 2-10.

WILEY, J. S., Jr. (1987). Antitrust and Core Theory. University of Chicago Law Review, 54(8), 556-589.

WILS, W. P. J. (2003). The Principle of Ne Bis in Idem in EC Antitrust Enforcement: A Legal and Economic Analysis. World Competition, 26(2), 131-148. 